\title{
Left Postpneumonectomy Syndrome Successfully Treated with Endobronchial Stent
}

\author{
Yoshinori Nakamura, Masahiro Ohata, Kazumi Kawabe, Akiko Ueda, \\ Kohji Iтон, Hisashi Fusimoto and Kazushi Kishi*
}

\begin{abstract}
We describe a case of left pneumothorax-induced left postpneumonectomy syndrome in the absence of anatomical anomalies developing at 10 years after the operation. We placed an endobronchial stent into the right truncus intermidius and the procedure resulted in recovery of the syndrome. We consider endobronchial stent placement as an effective treatment for postpneumonectomy syndrome, especially when surgical management is not feasible.

(Internal Medicine 37: 880-883, 1998)
\end{abstract}

Key words: lung cancer, pneumothorax

\section{Introduction}

Postpneumonectomy syndrome is a rare complication of right pneumonectomy occurring within the first postoperative year and is usually seen in children (1). But airway compression may occur after left, instead of right, pneumonectomy in the presence of congenital mediastinal anomalies including right aortic arch (2,3). We describe a case of left postpneumonectomy syndrome induced by left pneumothorax in the absence of such anomalies, occurring at as late as 10 years after left lung resection.

\section{Case Report}

A 75-year-old man underwent a left pneumonectomy under the diagnosis of limited squamous-cell lung cancer (TNM stage I) at the age of 65 at another hospital. He experienced gradually worsening shortness of breath year by year. Two days prior to admission to our hospital, he began to have fatigue and a weak sensation and became more severely dyspneic on exertion. On February 7, 1997, he noticed a tarry stool and was admitted to our hospital.

On examination, he was in poor general condition and had moderate respiratory failure with a respiration rate of 40 breaths a minute. His pulse rate was 110 beats $/ \mathrm{min}$. The blood pressure was 142 over $80 \mathrm{mmHg}$ and his body temperature was $38.5^{\circ} \mathrm{C}$. His weight was $53 \mathrm{~kg}$ and the height was $176 \mathrm{~cm}$.

Conjunctivae were normal and no cervical lymph nodes were palpable. There were mild moist rales heard over the right lung field on both inspiration and expiration. He was free of abdominal pain.

White blood cell count revealed $8,800 / \mathrm{mm}^{3}$ with a shift toward the left and C-reactive protein was raised to $14.8 \mathrm{mg} / \mathrm{dl}$. Other laboratory results were normal. Arterial blood gas analysis showed: $\mathrm{pH} 7.41$, partial pressure of oxygen $\left(\mathrm{PaO}_{2}\right) 42.2$ torr, and partial pressure of carbon dioxide $\left(\mathrm{PaCO}_{2}\right) 52.2$ torr while breathing ambient air. The chest radiographs revealed hyperinflation of the right lung and remarkable mediastinal shift into the left thoracic cavity (Fig. 1).

Upper gastrointestinal videoscopic examination disclosed a bleeding gastric ulcer, which was treated with a $\mathrm{H}_{2}$-blocking agent and the ulcer was cured. But on 4th hospital day his shortness of breath progressed to such a degree that ventilation assistance was required for severe hypoxemia and hypoventilation $\left(\mathrm{pH} 7.35, \mathrm{PaO}_{2} 34.3\right.$ torr, and $\mathrm{PaCO}_{2} 58.3$ torr while he was on nasal oxygen administration at 3 liters per minute).

Although antibiotic therapy relieved the inflammatory symptoms, his respiratory condition deteriorated on the 7th hospital day in spite of mechanical ventilation management. The chest $\mathrm{X}$-ray film revealed poor permeability in the lower lung field and the right diaphragm was ill-outlined compared with the film on admission (Fig. 2). The thoracic computed tomography (CT) scan showed low grade pneumothorax and severe narrowing of the right truncus intermidius caused by extreme mediastinal shift toward the postpneumonectomy space and compression

From the Department of Internal Medicine, Wakayama Medical College Kihoku Hospital, Wakayama and *the Department of Radiology, Wakayama Medical College, Wakayama

Received for publication January 16, 1998; Accepted for publication July 30, 1998

Reprint requests should be addressed to Dr. Yoshinori Nakamura, the Department of Internal Medicine, Wakayama Medical College Kihoku Hospital, 219 Myoji, Katsuragi-cho, Ito-gun, Wakayama 649-7113 


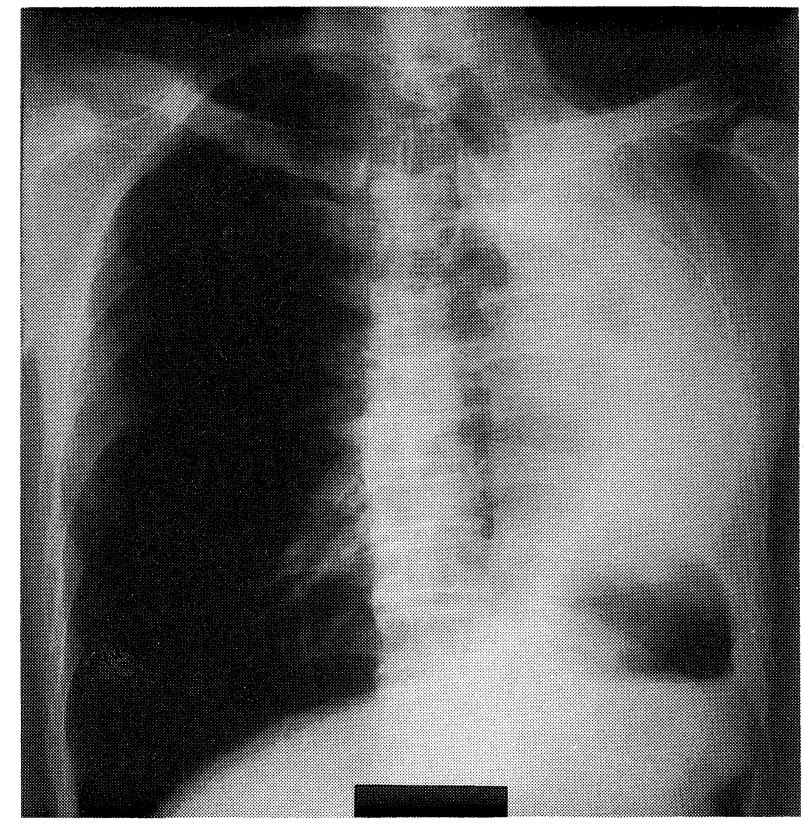

Figure 1. The chest radiograph on admission revealed hyperinflation of the right lung and remarkable mediastinal shift into the left thoracic cavity.

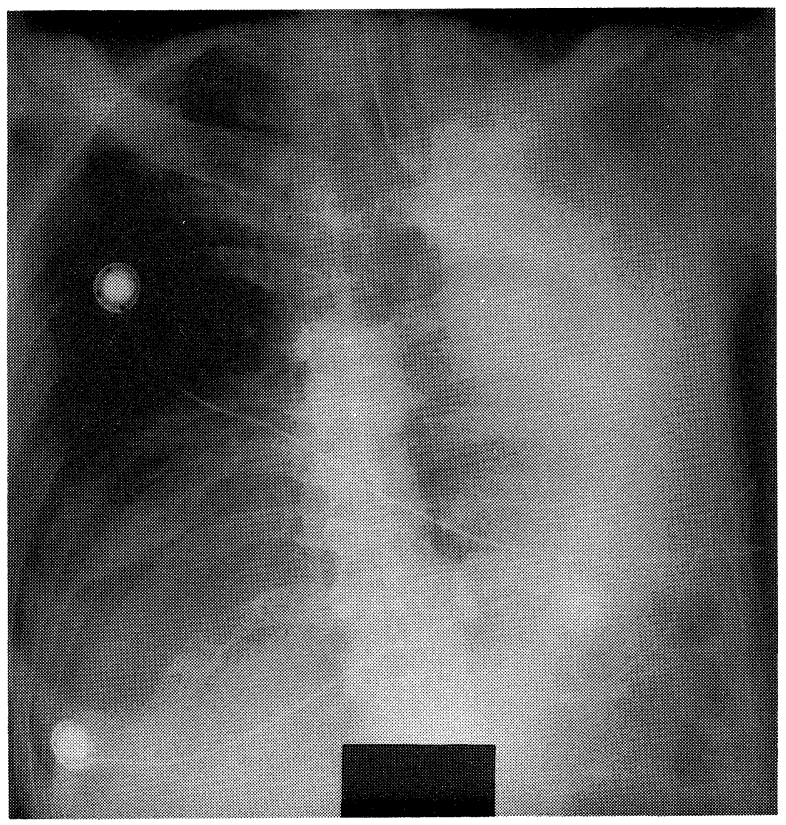

Figure 2. Chest $X$-ray film on 7th hospital day revealed poor permeability in the lower lung field and the ill-outlined right diaphragm.

by the right main pulmonary artery against the thoracic spine. His right middle and lower lung volume was markedly reduced (Fig. 3A, B).

Bronchoscopic examination through the endotracheal tube confirmed remarkable extrinsic compression of the truncus

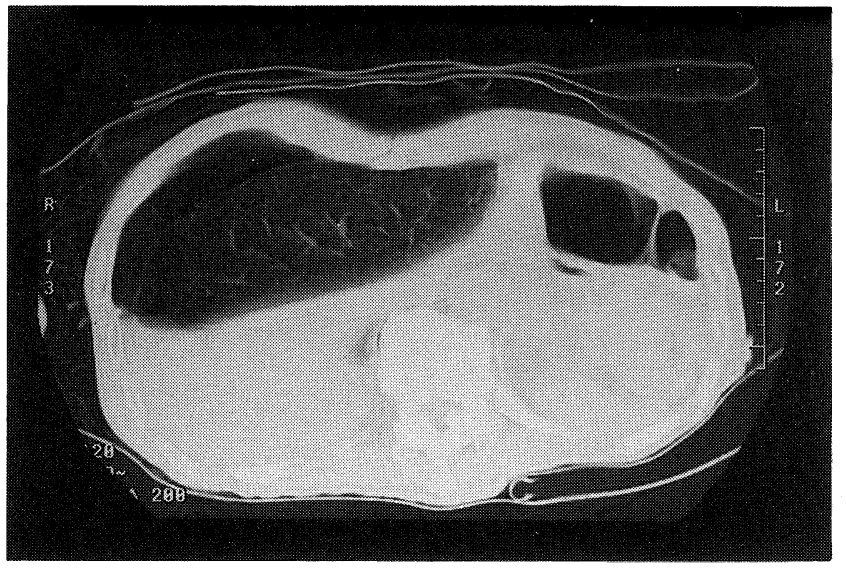

A

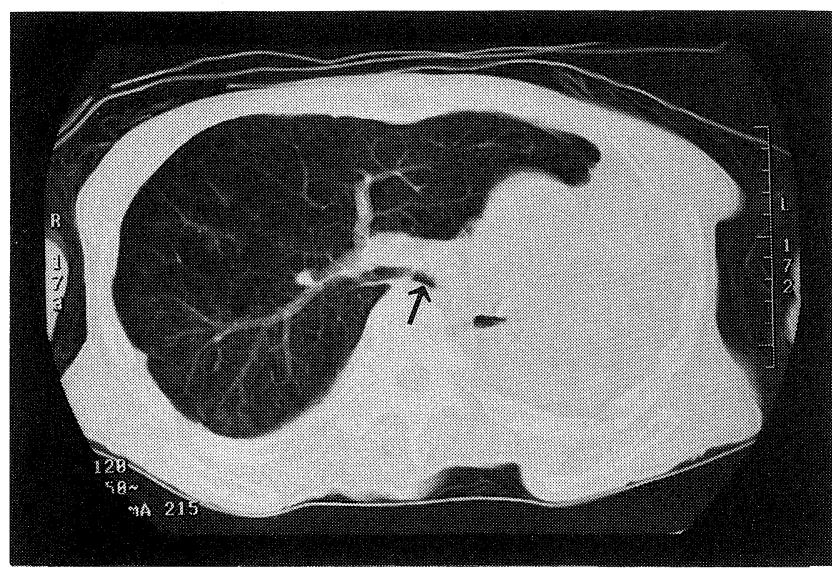

$\mathrm{B}$

Figure 3. Thoracic CT scan on 7th hospital day. 3A: Low grade pneumothorax. 3B: Severe narrowing of the right truncus intermidius caused by extreme mediastinal shift toward the postpneumonectomy space and compression by the right main pulmonary artery against the thoracic spine $(\rightarrow)$.

intermidius bearing normal bronchial mucus and an intact upper branch. There was little sputum or mucoid impaction. The airway lumen was nearly obliterated at the ostium of the truncus intermidius similar to bronchomalacia. We therefore conducted balloon dilatation therapy for the narrowed lesion using bronchofiberscopy only to fail in improving the condition.

Because the atelectases of the right middle and lower lobes remained unchanged despite the improvement in pneumothorax, we inserted an endobronchial stent into the right truncus intermidius on February 28 and we confirmed satisfactory dilatation of the stenotic lesion.

The chest X-ray films showed improved permeability in the right lower field (Fig. 4). Postoperative bronchoscopy showed an improvement in the airway diameter. He was extubated on March 19 without any event and recovered enough to be able to eat by himself and to walk around the bed. The arterial blood gas 
analysis improved: $\mathrm{pH} 7.43, \mathrm{PaO}_{2} 74.4$ torr, and $\mathrm{PaCO}_{2} 47.7$ torr while breathing 3 liters per minute by nasal cannula. Unfortunately we could not perform pulmonary function testing because of his limited performance status.

To our regret, on June 17, 1997 he suddenly died from cardiac arrest probably caused by acute myocardial infarction.

\section{Discussion}

Extreme mediastinal shift into the pneumonectomy cavity, hyperinflation of intact lung, heart failure (4) and cardiac

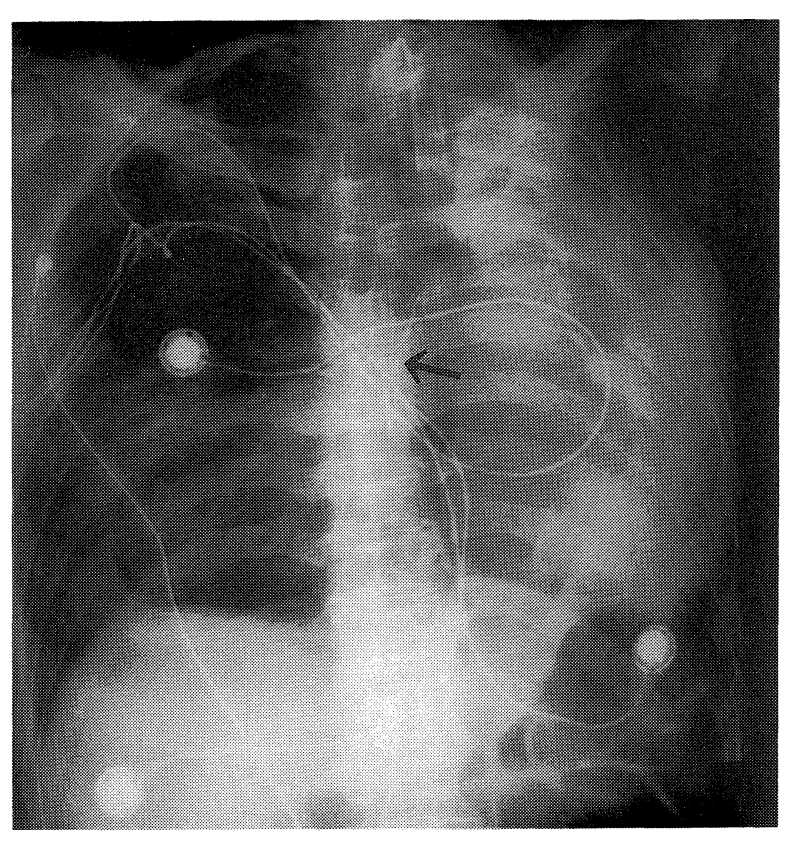

Figure 4. The chest X-ray film showed improved permeability in the right lower field by the endobronchial stent $(\rightarrow)$. herniation especially with pericardial incision (5-8) have been reported as complications of total lung resection.

Postpneumonectomy syndrome is a rare complication usually seen in young patients within the first year after right total lung resection. This report documents a case of left postpneumonectomy syndrome associated with no anatomical anomalies, which was induced by pneumothorax 10 years after left total lung resection.

There has been only four reports ( 7 cases) of left postpneumonectomy syndrome during the last 10 years (9-12). Characteristics of the 8 patients including the present case are presented in Table 1. Three cases were male and 5 were female, with a mean $( \pm S D)$ age of $38 \pm 24$ years. Their post-surgical diagnoses were lung cancer in four cases and interstitial emphysema, pulmonary carcinoid, aspergilloma and posttraumatic bronchial stricture, respectively in the remaining four cases. The interval from the time of pneumonectomy to the onset of the syndrome was over one year in all but case 2 and case 4 , with a mean $( \pm \mathrm{SD})$ duration of $54 \pm 54$ months. Ten years or more elapsed before the development of postpneumonectomy syndrome in case 7 as well as in the present case. Only case 1 had a right aortic arch but the other patients had no anatomical anomalies.

Management modalities for these patients are also presented in Table 1. Five patients $(62.5 \%)$ received surgical insertion of prostheses filled with saline. Case 6 and the present case underwent endobronchial stent placement, while case 1 was surgically treated to correct ligation and the right-sided ligamentum arteriosum. As for other treatment procedures, injection of sulfur hexafluoride into the postpneumonectomy pleural space was reported (4).

In summary, postpneumonectomy syndrome can occur after left total lung resection in spite of the absence of an anatomical anomaly (e.g. right aortic arch) at any age, and even a long time after operation. When a patient with pneumonectomy complains of progressive respiratory insufficiency, it is important to examine the airway to look for compression employing CT

Table 1. Cases of Left Postpneumonectomy Syndrome

\begin{tabular}{cccccccc}
\hline No. & $\begin{array}{c}\text { Age } \\
\text { (years) }\end{array}$ & Sex & $\begin{array}{c}\text { Preoperative } \\
\text { diagnosis }\end{array}$ & $\begin{array}{c}\text { Duration from } \\
\text { pneumonectomy } \\
\text { (months) }\end{array}$ & $\begin{array}{c}\text { Anatomical } \\
\text { anomaly }\end{array}$ & Treatment & Reference No. \\
\hline 1. & 0 & F & PIE & 24 & Right aortic arch & LDLA & 9 \\
2 & 21 & M & PC & 8 & $(-)$ & IPS & 10 \\
3 & 44 & F & LC & 14 & $(-)$ & IPS & 10 \\
4 & 63 & M & LC & 6 & $(-)$ & IPS & 10 \\
5 & 41 & F & LC & 67 & $(-)$ & IPS & 10 \\
6 & 34 & F & Aspergilloma & 48 & $(-)$ & PES & 11 \\
7 & 26 & F & PBS & 148 & $(-)$ & IPS & 12 \\
8 & 75 & M & LC & 120 & $(-)$ & PES & Our case \\
\hline
\end{tabular}

PIE: perinatal interstitial emphysema, PC: pulmonary carcinoid, LC: lung cancer, PBS: posttraumatic bronchial stricture, LDLA: ligation and division of right-sided ligamentum arteriosum, IPS: insertion of a prosthesis filled with saline solution, PES: placement of endobronchial stent. 


\section{Left Postpneumonectomy Syndrome}

and bronchoscopy. Since post pneumonectomy syndrome is a critical complication for patients with low pulmonary function, it is necessary to quickly examine and carefully treat them. Although mediastinal repositioning using a prosthesis filled with saline is a reasonable and safe procedure, we consider placement of an endobronchial stent as an equally effective treatment for postpneumonectomy syndrome, especially when surgical management (e.g. silastic prosthesis) is not feasible.

\section{References}

1) Evans GH, Clark RJ. Management of life threatening adult postpneumonectomy syndrome. Anesthesia 50: 148-150, 1995.

2) Grillo HC, Shepard JA, Mathisen DJ, Kanarek DJ. Postpneumonectomy syndrome: Diagnosis, management and results. Ann Thorac Surg 54: 638-650; discuss, 1992.

3) Manna L, Paras K. A case report of postpneumonectomy syndrome. Am J Crit Care 2: 168-170, 1993.

4) Terada $Y$, Matsumobe $S$, Toba $T$, Nemoto $T$, Tsuda $T$, Shimizu $Y$. Improvement of mediastinal shift after left pneumonectomy by injection of sulfur hexafluoride. Nippon Kyobu Geka Gakkai Zasshi (Jpn J Respir) 39: 113-115, 1991.

5) Baaijens PF, Hasenbos MA, Lacquet LK, Dekhuijzen PN. Cardiac herniation after pneumonectomy. Acta Anaesthesiol Scand 36: 842-845, 1992.

6) Errando CL, Rico GR, Rodriguez G, Silla I, Chiveli MA, Ortega MC. Case 5-1994. Cardiac herniation: a severe postoperative complication of intrapericardial pneumonectomy. J Cardiothorac Vasc Anesth 8: 584588, 1994 (clinical conference).

7) Nakajima Y, Takahashi T, Iwahashi M, Sakai S, Yokoyama A, Shiraishi Y. Cardiac herniation after right pneumonectomy. Masui (Jpn J Anaesth) 41: 1319-1321, 1992.

8) Nishiuchi S, Okazaki T, Shinkai M, Fuziwara H, Nasu M, Shomura T. A case of cardiac herniation following intrapericardial pneumonectomy after induction chemoradiotherapy. Nippon Kyobu Geka Gakkai Zasshi (Jpn J Respir) 44: 63-68, 1996.

9) Quillin SP, Shackelford GD. Postpneumonectomy syndrome after left lung resection. Radiology 179: 100-102, 1991.

10) Shamji FM, Deslauriers J, Daniel TM, Matzinger FR, Mehran RJ, Todd TR. Postpneumonectomy syndrome with an ipsilateral aortic arch after left pneumonectomy. Ann Thorac Surg 62: 1627-1631, 1996.

11) Cordova FC, Travaline JM, O'Brien GM, Ball DS, Lippmann M. Treatment of left pneumonectomy syndrome with an expandable endobronchial prosthesis. Chest 109: 567-570, 1996.

12) Boiselle PM, Shepard JA, McLoud TC, Grillo HC, Wright CD. Postpneumonectomy syndrome: Another twist. J Thorac Imaging 12: 209-211, 1997. 